\title{
DETERMINATION OF 5-HYDROXYINDOLE-3-ACETIC ACID IN WASTEWATER BY HIGH PERFORMANCE LIQUID CHROMATOGRAPHY COUPLED WITH TANDEM MASS SPECTROMETRIC DETECTION
}

\section{(C) Mongjoo Jang1, Vladislav D. Chernyshov1, Andrey V. Pirogov1, Olga G. Tataurova', Vladimir V. Rozhanets ${ }^{3}$, Oleg A. Shpigun'}

1 Lomonosov Moscow State University, Division of Analytical Chemistry, Moscow, Russia; e-mail: mongjoo0813@gmail.com

2 Frumkin Institute of Physical chemistry and Electrochemistry of the RAS, Moscow, Russia; e-mail: info@biasep.ru

3 Serbsky Federal medical research center of Psychiatry and Narcolgy of the Ministry of Health of the Russian Federation, Moscow, Russia; e-mail: vladimirroz@mail.ru

Submitted December 20, 2017.

Analysis of biomarkers in wastewater is increasingly seen as an important tool for valuation of health, nutrition and use of various substances by humans. Some biomarkers are used for population estimates, since the actual values of population size in cities can differ significantly from official counts, which inevitably leads to errors in assessing the impact of various factors to people calculated per capita. 5-hydroxyindole-3-acetic acid (5-HIAA) is the main metabolite of serotonin, which is excreted by urine and can be used as a biomarker for population estimates. The determination of this metabolite is more preferred than the detection of serotonin itself in terms of correctness of the results. A technique of extraction and subsequent quantitative determination of 5-HIAA in wastewater by high-performance liquid chromatography in combination with tandem mass spectrometric detection was developed. Poroshell Hilic column was used as a stationary phase which has an alternative selectivity compared to traditional C18 columns. Developed procedure is characterized by low detection limits $(0.2 \mu \mathrm{g} /$ liter $)$ and good selectivity. The conditions for liquid-liquid extraction of 5 -HIAA from wastewater were selected. This technique provides reliable estimation of the concentration of 5-HIAA in wastewater.

Keywords: 5-hydroxyindole-3-acetic acid; biomarkers; high performance liquid chromatography; mass spectrometry; wastewater; liquid-liquid extraction.

\section{INTRODUCTION}

Analysis of biomarkers in wastewater is increasingly seen as an important tool for valuation of health, nutrition and use of various substances by humans. Biomarkers get into the wastewater by excretion from human body with urine and feces. Some biomarkers, for example, artificial sweeteners, nicotine and its metabolites, caffeine, etc., are used for population estimates since the actual values of population size in cities can differ significantly from official counts, which inevitably leads to errors in assessing the impact of various factors to people calculated per capita [1,2].

The results of the study completely depend on the choice of biomarkers. Therefore, a potential biomarker must satisfy the following criteria $[3,4]$ : possibility of determination;

small affinity to solid particles in wastewater and filtration systems (including filters during sample preparation);

stability in wastewater during transportation and storage and throughout the analysis;

constant excretion from the body;

concentration of biomarkers should be unambiguously correlated with the population size;

low dispersion and known amount of daily excretion of the biomarker per capita;

excretion of biomarker from the body should not be influenced by such factors as weather, season, geographical location.

5-hydroxyindole-3-acetic acid (5-HIAA) is the main metabolite of serotonin excreted by urine. 
The determination of this metabolite is more preferred than the detection of serotonin itself. Content of 5-hydroxyindole-3-acetic acid in the wastewater decreases 3 times in 7 days at room temperature. However, when it is stored in a refrigerator/freezer $\left(+4 /-20^{\circ} \mathrm{C}\right)$ or acidified to $\mathrm{pH} 2$, the acid is stable for two weeks [5].

Unfortunately, the specific level of 5-HIAA in wastewater is not provided in literature. The level of 5-hydroxyindole-3-acetic acid in the wastewater of Valencia varies from 5.5 to $14.3 \mu \mathrm{g} /$ liter [2]. There are numerous methods for the determination of 5-HIAA in urine by HPLC-MS/MS. However, there are only two works in literature devoted to the determination of this compound in wastewater with detection limits up to $1 \mu \mathrm{g} / \mathrm{liter}[2,5]$. Considering such low and varied concentration of 5-HIAA in wastewater, it is vital to develop a reliable and highly sensitive procedure for the determination of 5-HIAA by high performance liquid chromatography coupled with tandem mass spectrometric detection.

\section{EXPERIMENTAL}

Reagents and Instruments. 5-hydroxyindole3 -acetic acid (Sigma Aldrich, Switzerland, $\geq 98 \%$ ), methanol, acetonitrile, formic acid, ammonia (25\%, aq.), ammonium acetate, chloroform, hexane (all Panreac, Spain, puriss.), methyl tert-butyl ether, dichloromethane, ethyl acetate (Component Reactive, Russia, p.a.), acetic acid (Himmed, Russia, puriss.), deionized water, wastewater samples.

LC-MS/MS analyses were carried out with Ultimate 3000 (Dionex, USA) interfaced to TSQ Endura triple-stage quadrupole mass spectrometer (Thermo Scientific, USA) with electrospray ionization. Data collection and interpretation of chromatograms were performed by software Xcalibur (Thermo Scientific, USA). The chromatography was carried out using $4.6 \mathrm{~mm} \times 250 \mathrm{~mm}$ Agilent Poroshell 120 HILIC $(4 \mu \mathrm{m})$. Single channel pipettes with variable volume range $10-100 \mu \mathrm{L}, 20-$ $200 \mu \mathrm{L}, 100-1000 \mu \mathrm{L}, 1000-5000 \mu \mathrm{L}$ (LABMATE, Poland) were used for sampling aliquots (limit of permissible relative error of measurement didn't exceed $\pm 5 \%$ ). Accurate weighing of the samples was carried out on ExplorerPro scales (Ohaus Corporation, USA) with the accuracy $0.0001 \mathrm{~g}$. Centrifugation of the samples was performed using CM-50 (Elmi, Latvia) and SIGMA 1-15P (Sigma, Germany) centrifuges. For ultrasonic liquid-liquid extraction and degasation of the mobile phase ultrasonic bath UZV-4.0 (PKF Sapphire, Russia) was used. Rotary evaporator with automatic vacuum station (Buchi, Switzerland) was used for the evaporation of organic solvents. $\mathrm{pH}$ of solutions was measured by $\mathrm{pH}$ meter PB-11 (Sartorius AG, Germany). Vacuum system and pump Buchi V-100 (Switzerland) were purposed for the solid-phase extraction.

Pretreatment of wastewater samples. Working solutions were prepared directly on the day of analysis by diluting aliquots of the stock solution with deionized water. During preparation wastewater samples were centrifuged for 5 min $(15,000 \mathrm{rpm})$, passed through "White ribbon" filter and extracted.

Liquid-liquid extraction (LLE). Following organic solvents were chosen for the study of LLE: ethyl acetate, hexane, chloroform, dichloromethane, tert-butyl methyl ether, hexane/diethyl ether (50:50). Ethyl acetate was used as an organic phase for LLE because of its reproducibility and the degree of extraction.

LLE procedure: to decrease $\mathrm{pH}$ to $2.720 \mu \mathrm{L}$ of formic acid was added to $2 \mathrm{~mL}$ of wastewater sample contained in glass tube. Then $2 \mathrm{~mL}$ of ethyl acetate was added. The solution was shaken over $10 \mathrm{~min}$ on multivortex and centrifuged for $2 \mathrm{~min}$ at $3000 \mathrm{rpm} .1 .5 \mathrm{~mL}$ of organic phase was collected and evaporated in concentrator until dryness. The dry residue was dissolved in $200 \mu \mathrm{L}$ of mobile phase, stirred for $10 \mathrm{~min}$ and centrifuged for $5 \mathrm{~min}$ at $14000 \mathrm{rpm}$.

Conditions for LC-MS/MS. The column was thermostated at $30^{\circ} \mathrm{C}$. Injection volume was $20 \mu \mathrm{L}$. Isocratic elution with $0.1 \%$ formic acid/acetonitrile (50:50) was used at a flow rate $0.7 \mathrm{~mL} / \mathrm{min}$. Mass spectrometer parameters were selected using TSQ Endura Tune software (Thermo Scientific, USA). The mass spectrometer operated in the positive ion mode using electrospray ionization. Voltage on capillary was $4.0 \mathrm{kV}$, sheath gas flow was 12 liter $/ \mathrm{min}$, the vaporizer temperature $-440^{\circ} \mathrm{C}$, the ion transfer tube temperature $-360^{\circ} \mathrm{C}$. Collision cell voltage $-5 \mathrm{~V}$, fragmentator voltage $-10 \mathrm{~V}$. For the determination of 5-HIAA in MRM mode the following transitions were monitored: $\mathrm{m} / z \quad 192 \rightarrow \mathrm{m} / z$ 146, $m / z 192 \rightarrow m / z 117$. The collision energy for the first transition was set at $10 \mathrm{eV}$, for the second one $-36 \mathrm{eV}$. The scanning time for one transition was $200 \mathrm{msec}$.

\section{RESULTS AND DISCUSSION}

Significant amount of contaminants in wastewater is sorbed by suspended fine particles. In this regard, the right choice of conditions for the extraction of 5-hydroxyindole-3-acetic acid is an important step of analysis.

Sorbents for solid-phase extraction. Extraction recoveries are presented in Table 1 . It can be seen 


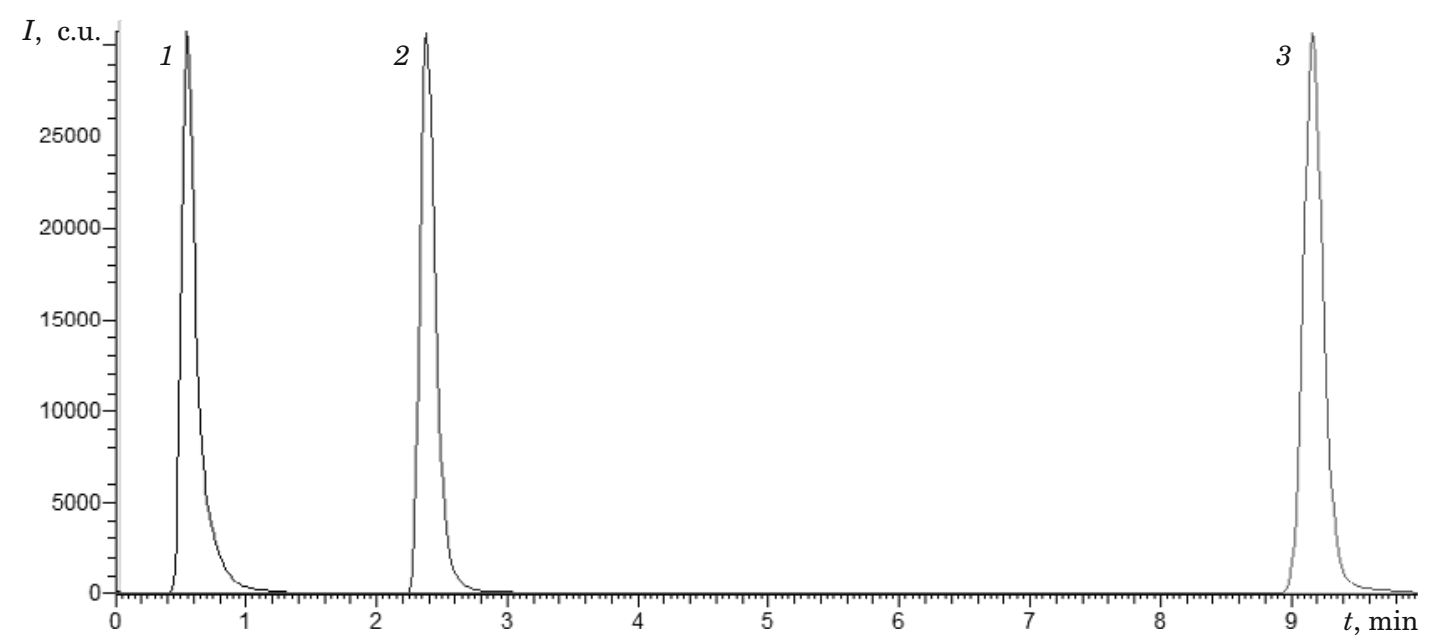

Fig. 1. Overlay of chromatograms of 5-HIAA obtained using the following columns: 1 - Eclipse Plus C18 RRHD; 2 - Zorbax Eclipse C18; 3 - Poroshell HILIC (injection volume $10 \mu \mathrm{L} ; \rho_{5 \text {-HIAA }}=2 \mu \mathrm{g} / \mathrm{mL}$; mobile phase: $0.1 \%$ formic acid: acetonitrile (50:50); flow rate $0.3 \mathrm{~mL} / \mathrm{min}$; detection mode: total ion current (TIC), ESI)

that the highest extraction recovery was obtained on Strata-X.

However, despite this sorbent had the best among the studied values of the extraction recovery of 5-HIAA from wastewater, the reproducibility of the results was insufficient. On this basis, it was concluded that probably liquid-liquid extraction was preferred to be used.

Liquid-liquid extraction conditions. In this paper a comparative experiment with various extractants, such as ethyl acetate, hexane, chloroform, dichloromethane, tert-butyl methyl ether, and mixture of hexane/diethyl ether (50:50), for the extraction of standard solution of 5-HIAA with concentration level $20 \mu \mathrm{g} / \mathrm{liter}$ was carried out. During the experiment various values of $\mathrm{pH}(2.7,4.6,6.5)$ were tested for the best value of extraction recoveries and reproducibility of extraction. The results are shown in Table 2.

It was found that extraction recovery of 5-HIAA significantly depends on the $\mathrm{pH}$ of the solutions and increases with decreasing of $\mathrm{pH}$. The maximum recovery (74\%) was obtained using ethyl acetate at $\mathrm{pH} 2.7$.

Microemulsions (ME) are known as colloid systems potentially capable to extract compounds effectively [6]. The term "microemulsion" refers to

Table 1. Extraction recovery of 5 -HIAA $(\rho=20 \mu \mathrm{g} / \mathrm{liter})$ from standard solution by solid-phase extraction using various cartridges $(n=3 ; P=0.95)$

\begin{tabular}{ccccc}
\hline $\mathrm{pH}$ & Strata-X & $\begin{array}{c}\text { Chromabond } \\
\text { C18 }\end{array}$ & $\begin{array}{c}\text { Chromabond } \\
\text { HR-P }\end{array}$ & $\begin{array}{c}\text { AccuBOND } \\
\text { C18 }\end{array}$ \\
\hline 2.7 & 0 & $41 \pm 9$ & 0 & $37 \pm 2$ \\
4.6 & $63 \pm 13$ & $31 \pm 10$ & $5 \pm 1$ & $24 \pm 3$ \\
6.3 & $50 \pm 10$ & $3 \pm 2$ & 0 & 0 \\
\hline
\end{tabular}

systems that are fundamentally different from conventional macroemulsions. Typically, ME contain four components: water, hydrocarbon ("oil"), colloid surfactant and non-micellizing surfactant, for example, butyl alcohol. Microemulsion is a thermodynamically stable dispersed system, which is formed by "oil" and water and stabilized with the help of surfactants and co-surfactants. In this case any organic compound limitedly soluble in water could be "oil." Since the emergence of thermodynamically stable phase is based on the principles of self-organization of surfactants, microemulsion phases are in many respects similar to other organized systems of surfactants, for example, micellar solutions. Earlier we showed that when calcium chloride was added to ME based on sodium dodecyl sulfate (SDS), the system became thermodynamically unstable and formed two immiscible phases: "oil" and water [7]. Hydrophobic substances pass into the oil phase after separation and thereby are concentrated due to a solvent volume decrease (ap-

Table 2. Extraction recovery of 5-HIAA ( $\rho=20 \mu \mathrm{g} /$ liter $)$ from standard solution by LLE at various value of $\mathrm{pH}$ $(n=3 ; P=0.95)$

\begin{tabular}{lccc}
\hline & \multicolumn{3}{c}{ Standard solution } \\
\cline { 2 - 4 } Extractants & $\begin{array}{c}\text { Ammonium } \\
\text { Water, } \\
\text { acetate } \\
\text { buffer, } \\
\mathrm{pH}=4.6\end{array}$ & $\begin{array}{c}\text { Formic } \\
\text { acid, } \\
\mathrm{pH}=2.7\end{array}$ \\
\hline Ethyl acetate & $26 \pm 3$ & $51 \pm 4$ & $74 \pm 3$ \\
Hexane & $2 \pm 1$ & $7 \pm 2$ & $9 \pm 1$ \\
Chloroform & 0 & 0 & $52 \pm 4$ \\
Dichloromethane & $3 \pm 1$ & $10 \pm 2$ & $16 \pm 3$ \\
Tert-butyl methyl ether & $63 \pm 10$ & $48 \pm 4$ & $73 \pm 3$ \\
Hexane/diethyl ether (50:50) & $10 \pm 1$ & $12 \pm 2$ & $15 \pm 2$ \\
\hline
\end{tabular}




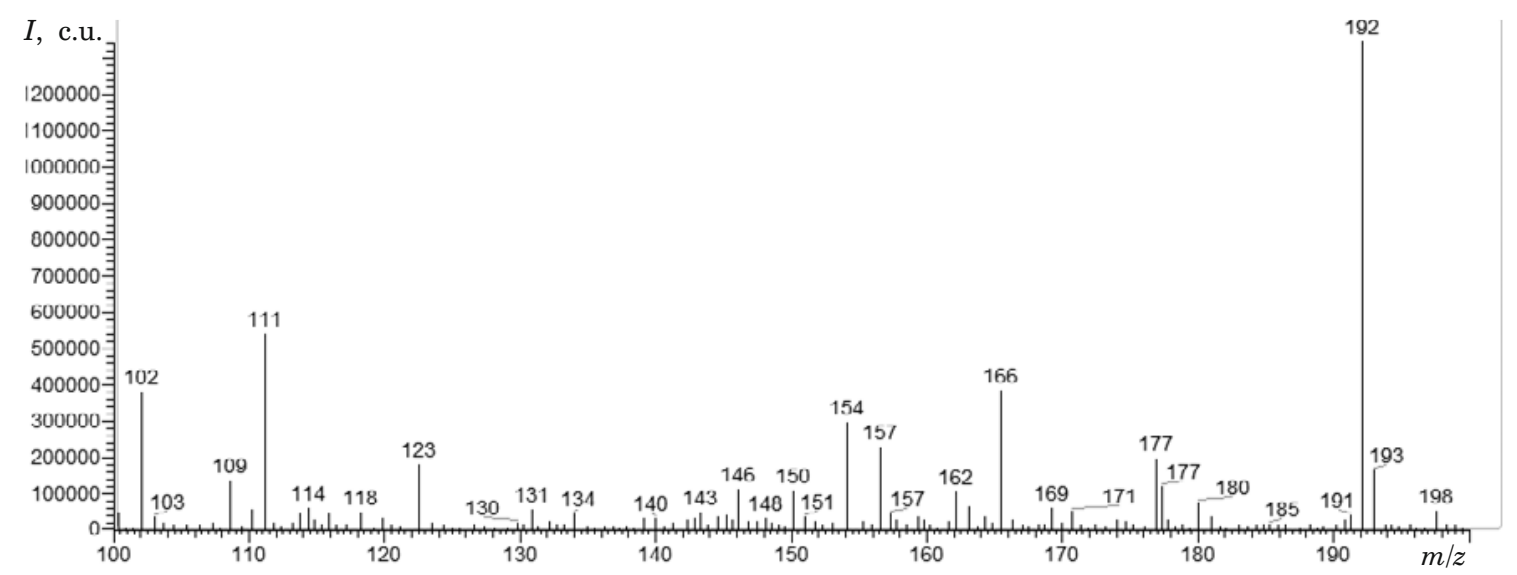

Fig. 2. Mass spectrum of $1 \mu \mathrm{g} / \mathrm{mL}$ solution of 5-HIAA (detection mode: TIC in the range of $m / z: 100-200$ )

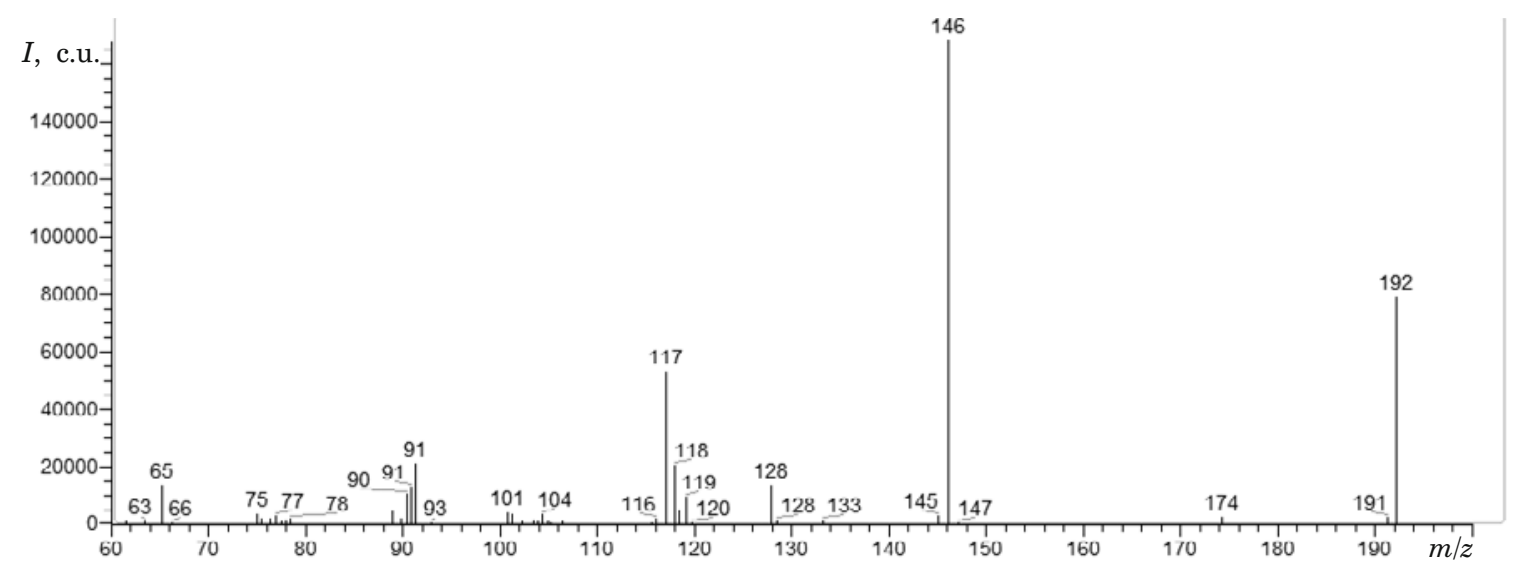

Fig. 3. Mass spectrum of product ions of 5 -HIAA $(\mathrm{CE}=50 \mathrm{eV}$; column: Poroshell $120 \mathrm{HILIC} 250 \times 4.6 \mathrm{~mm} \times 4 \mu \mathrm{m}$; injection volume: $20 \mu \mathrm{L} ; \rho_{5 \text {-HIAA }}=1 \mu \mathrm{g} / \mathrm{mL}$; mobile phase: $0.1 \%$ formic acid: acetonitrile $(50: 50)$, flow rate $\left.0.7 \mathrm{~mL} / \mathrm{min}\right)$

proximately by 10 times). When using the reverse microemulsions "water-in-oil" after decomposition of ME, the hydrophilic substances are concentrated in the aqueous phase. We tested the reverse microemulsion of $65 \% n$-heptane, $6 \%$ SDS, $5 \%$ water, $23 \% n$-butanol as an extractant. However, it was found that extraction recovery and reproducibility of the results were not high, and it was not used throughout the further work.

Stationary phase. 5-HIAA is hydrophilic compound $(\log P 1.28)$, therefore it is advisable to use a stationary phase with polar endcapping, ensuring good retention of nonpolar and high-polar compounds. Stationary phases with various functional groups were compared. Chromatograms are shown in Fig. 1.

When C18 was used as a stationary phase, asymmetry of the chromatographic peak was observed. The maximum number of theoretical plates $(35200 \pm 700 \mathrm{tp} / \mathrm{m})$ was obtained using the Agilent Poroshell 120 HILIC column. To reduce the analysis time, the temperature of the column thermostat was varied from 25 to $45^{\circ} \mathrm{C}$. The thermostat temperature was set to $30^{\circ} \mathrm{C}$.
MRM parameters: collision energy and fragmentator. To find the optimal conditions for mass spectrometric detection of 5-HIAA $(1 \mu \mathrm{g} / \mathrm{mL})$ in direct injection mode, a solution of 5-HIAA was scanned in the total ion current mode from $\mathrm{m} / z 100$ to 200 .

The mass of the initial 5-HIAA ion equal to 192 was selected in terms of the most intense peak (Fig. 2). The greatest sensitivity can be achieved by using the MRM mode in the version of tandem mass spectrometric detection. In Fig. 3, the mass spectrum of product ions is given at the collision energy of $50 \mathrm{eV}$.

For quantitative analysis the most intensive MRM-transition is usually chosen. Also an additional transition with a second maximum value of $\mathrm{m} / \mathrm{z}$ is selected for confirmation. The following MRM-transitions for determination of 5-HIAA were chosen: $\mathrm{m} / z \quad 192 \rightarrow \mathrm{m} / z \quad 146, \mathrm{~m} / \mathrm{z} 192 \rightarrow \mathrm{m} / \mathrm{z}$ 117.

Intensity of the signal of a certain MRM-transition is strongly influenced by the collision energy (CE). CE basically depends on the stability of the precursor ion and the required degree of its frag- 


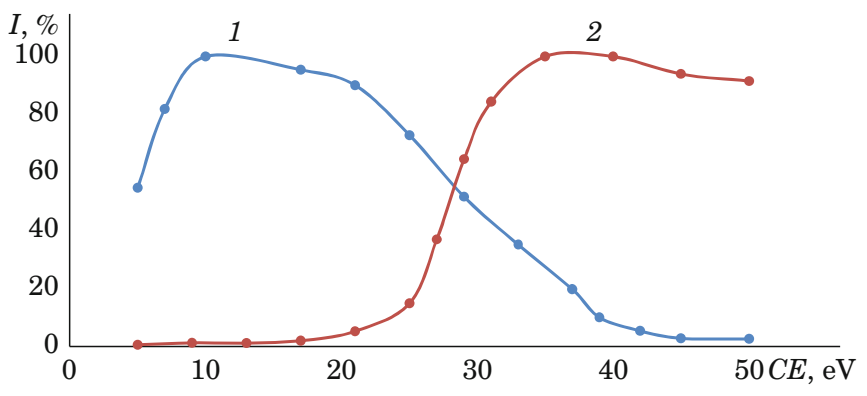

Fig. 4. Dependence of the intensity of the transition signals $m / z 192 \rightarrow m / z 146$ (1), $m / z 192 \rightarrow m / z 117$ (2) from the values of collision energy

mentation. To select the values of $\mathrm{CE}$ at which the maximum intensity is observed, the dependences of signal intensity on CE were plotted (Fig. 4). The collision energy $10 \mathrm{eV}$ was selected for the transition $\mathrm{m} / z 192 \rightarrow \mathrm{m} / z 146$ and $36 \mathrm{eV}$ for $\mathrm{m} / z 192 \rightarrow$ $\rightarrow m / z 117$.

The fragmentator voltage can have a significant effect on the ionization yield of the sample and accordingly, on the sensitivity of determination. The dependence of the signal intensity of 5-HIAA from the fragmentator voltage was plotted (Fig. 5). To find the optimal fragmentation potential, the intensities of the signals of MRM-transitions from 50 to $150 \mathrm{~V}$ with increments of $20 \mathrm{~V}$ were compared. The optimum value of the fragmentator voltage was found to be $90 \mathrm{~V}$.

Linearity. To evaluate the metrological characteristics of the proposed approach for the determination of 5-HIAA by HPLC-MS/MS under the selected conditions, a calibration curve was plotted for series of 8 test solutions with an acid concentration in the range from 0.5 to $100 \mu \mathrm{g} /$ liter.

The linear regression equation for the dependence of the peak area on the concentration of 5-HIAA is: $S=(720.9 \pm 30.8) c_{i}+(5607.3 \pm 470.1)$, $r=0.995$, linear range $-0.5-100 \mu \mathrm{g} /$ liter.

The detection limit is $0.2 \mathrm{\mu g} / \mathrm{liter}$ with a preconcentration in 7.5 times.

Precision. The precision of the procedure was evaluated by determining the convergence of results by repeating the analysis on 6 samples by one chemist on the same day in one equipment and determining the interlaboratory precision when analyzing the same sample in the same laboratory, with a complete repetition of the sample preparation procedure and measurement by another chemist. Convergence was evaluated by calculating the relative standard deviation (RSD) obtained from sequential determinations performed by one chemist on one day. The evaluation of interlaboratory precision with the established confidence interval was determined according to the $F$-test of Fisher

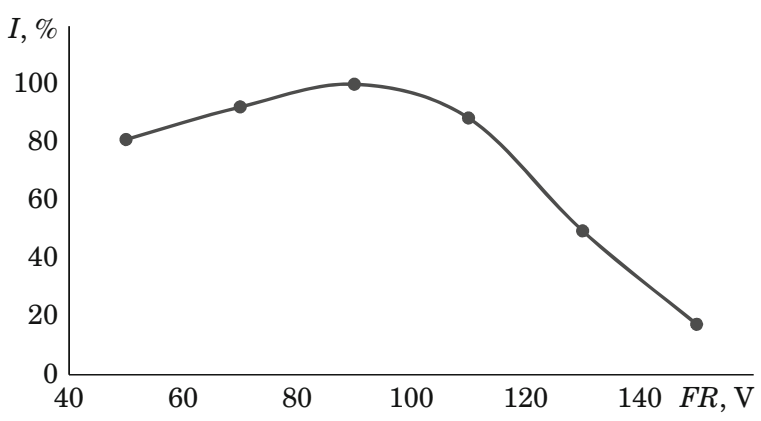

Fig. 5. Dependence of intensity of the signal of 5-HIAA on the fragmentator voltage for the selected MRM-transitions

and the Student's $t$-test. The results are shown in Table 3.

It is shown that the technique has good convergence (RSD less than 5\%) and interlaboratory precision, in view of the fulfillment of all eligibility criteria.

Solution stability. The stability of the model solution at room temperature $\left(25^{\circ} \mathrm{C}\right)$ was investigated. The sample was analyzed immediately after preparation, in $30 \mathrm{~min}, 60 \mathrm{~min}$ and further until the difference with the initial measurement was more than $5.0 \%$. It was found that the solution is stable for 24 hours.

Correctness. Correctness was assessed by the method of additives. As a result, it is obtained that the proposed method is correct.

Robustness. During the study of the robustness of the method, it was found that the variation of the chromatographic parameters: the composition of the mobile phase (acetonitrile $\pm 5 \%$ ), column temperature $\left( \pm 5^{\circ} \mathrm{C}\right)$, flow rate $( \pm 0.2 \mathrm{~mL} / \mathrm{min})$ have no significant effect on the determined amount of

Table 3. Interlaboratory precision of the determination of 5-HIAA by HPLC-MS/MS

\begin{tabular}{|c|c|c|}
\hline \multirow{2}{*}{$N$} & \multicolumn{2}{|c|}{$S_{5 \text {-HIAA }}$, c.u. $\left(c_{5 \text {-HIAA }}=10 \mathrm{\mu g} /\right.$ liter $)$} \\
\hline & Chemist 1 & Chemist 2 \\
\hline 1 & 28946 & 28634 \\
\hline 2 & 29783 & 28013 \\
\hline 3 & 28696 & 28910 \\
\hline 4 & 29168 & 28978 \\
\hline 5 & 28934 & 29012 \\
\hline 6 & 29465 & 28634 \\
\hline Average & 28972 & 28697 \\
\hline $\mathrm{SD}$ & 398.30 & 373.99 \\
\hline $\mathrm{RSD}, \%$ & 1.37 & 1.30 \\
\hline \multicolumn{2}{|c|}{ Calculated $F$-value } & 1.13 \\
\hline \multicolumn{2}{|c|}{$F$-Table value $(0.95,5,5)$} & 5.05 \\
\hline \multicolumn{2}{|c|}{ Calculated Student's $t$-value } & 2.10 \\
\hline \multicolumn{2}{|c|}{ Student's $t$-table value $(0.95,10)$} & 2.23 \\
\hline
\end{tabular}




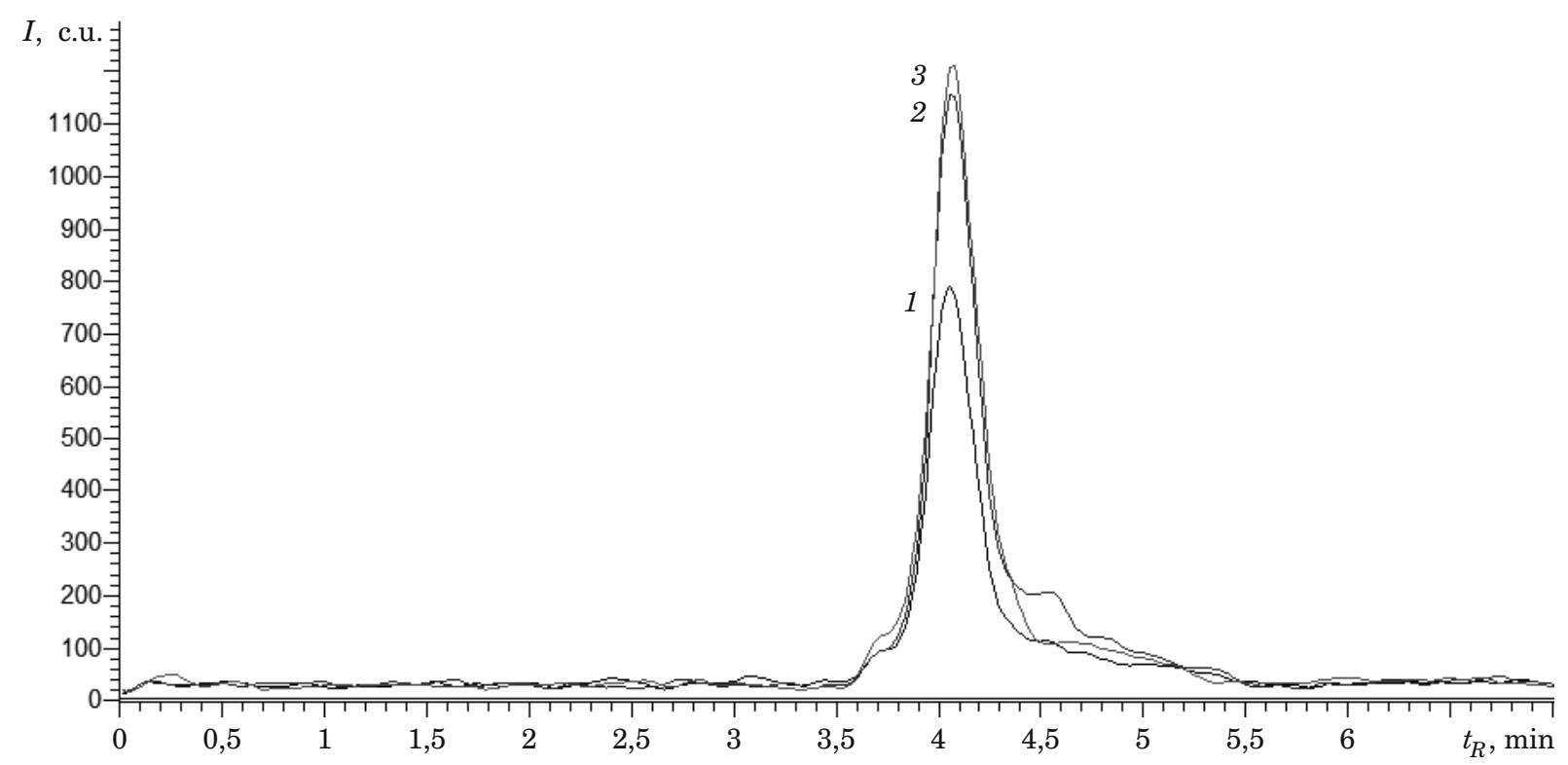

Fig. 6. Overlay of chromatograms of wastewater samples: 1 - \#1;2 - \#2;3 — \#3 (column: Poroshell 120 HILIC $4.6 \times 250 \mathrm{~mm}, 4 \mu \mathrm{m}$ ); mobile phase: $0.1 \%$ formic acid/acetonitrile $50: 50$; flow rate $0.7 \mathrm{~mL} / \mathrm{min}$; column temperature $30^{\circ} \mathrm{C}$; detection in MRM mode with positive ESI; MRM-transitions are $m / z 192 \rightarrow m / z 146(10 \mathrm{eV}), 117$ (36 eV); injection volume $20 \mu \mathrm{L})$

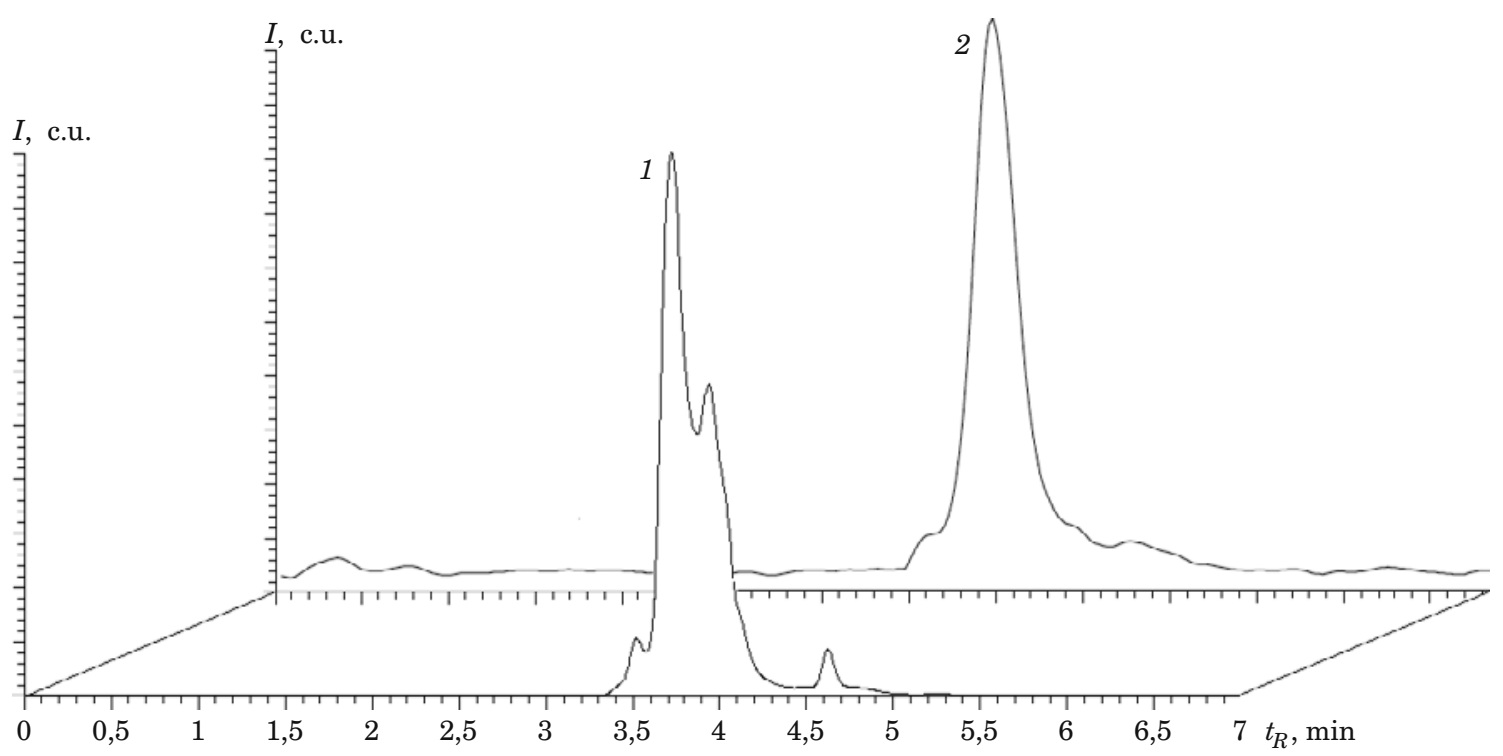

Fig. 7. Overlay of chromatograms of the wastewater sample \#1: $1-\operatorname{HPLC}-\mathrm{UV}(\Lambda=275 \mathrm{~nm})$; $2-\mathrm{HPLC}-\mathrm{MS} / \mathrm{MS}$ (column: Poroshell 120 HILIC $4.6 \times 250 \mathrm{~mm}, 4 \mu \mathrm{m}$; mobile phase: $0.1 \%$ formic acid/acetonitrile 50:50; flow rate $0.7 \mathrm{~mL} / \mathrm{min}$; column temperature $30^{\circ} \mathrm{C}$; injection volume $20 \mu \mathrm{L}$ )

5-HIAA by HPLC-MS/MS. The relative deviation does not exceed $10.0 \%$.

Analysis of real objects. As an example of the analysis of real objects, wastewater samples were

Table 4. The results of the determination of 5 -HIAA by HPLC-MS/MS in real objects $(n=3 ; P=0.95)$

\begin{tabular}{lcc}
\hline Object & Concentration, $\mu \mathrm{g} /$ liter & $s_{r}, \%$ \\
\hline Wastewater (\#1) & $7.9 \pm 0.4$ & 4 \\
Wastewater (\#2) & $15.8 \pm 1.1$ & 6 \\
Wastewater (\#3) & $18.1 \pm 1.0$ & 4 \\
\hline
\end{tabular}

taken at three wastewater treatment plants in Moscow region. The results of the determination of 5-HIAA in wastewater samples are shown in Table 4. Overlay of the obtained chromatograms in the analysis of wastewater is shown in Fig. 6. Overlay of chromatograms of wastewater obtained by HPLC-UV $(\Lambda=275 \mathrm{~nm})$ and HPLC-MS/MS is shown in Fig. 7.

\section{CONCLUSION}

Procedure for a highly sensitive determination of 5-hydroxyindole-3-acetic acid in wastewater by 
high-performance liquid chromatography with tandem mass spectrometric detection was developed. The metrological characteristics of the determination of 5-HIAA by HPLC-MS/MS with preliminary sample preparation by LLE are evaluated. Following technique is characterized by low detection limits $(0.2 \mu \mathrm{g} /$ liter $)$ and good reproducibility $\left(s_{r}=4-\right.$ $6 \%$ ). It is used for the determination of 5-HIAA in wastewater collected at three wastewater treatment plants in Moscow region. The content of 5-HIAA in wastewater was found to be from 8 to $18 \mu \mathrm{g} / \mathrm{liter}$.

Acknowledgment. The work was carried out with financial support of the RFBR grant 16-03-00257.

\section{REFERENCES}

1. Rozhanets V. V., Jang M. Sewage-based epidemiology: assessment of consumption of ethanol and nicotine / Narkologiya. 2017. Vol. 16. N 8. P. $11-23$ [in Russian].
2. Rico M., Andrés-Costa M. J., Picó Y. Estimating population size in wastewater-based epidemiology. Valencia metropolitan area as a case study / J. Hazard. Mater. 2017. Vol. 323. P. $156-165$.

3. Gracia-Lor E., Bade R., Bijlsma L. Measuring biomarkers in wastewater as a new source of epidemiological information: Current state and future perspectives / Environ. Int. 2017. Vol. 99. P. $131-150$.

4. McCall A.-K., Bade R., Kinyua J., et al. Critical review on the stability of illicit drugs in sewers and wastewater samples / Water Res. 2016. Vol. 88. P. 933 - 947.

5. Chen C., Kostakis C., Gerber J. P. Towards finding a population biomarker for wastewater epidemiology studies / Sci. Total Environ. 2014. Vol. 487. N 1. P. 621 - 628.

6. Winsor P. A. Hydrotropy, solubilisation and related emulsification processes. Part 1 / Trans. Faraday Soc. 1948. Vol. 44. P. $376-398$.

7. Tolmacheva N. G., Pirogov A. V., Shpigun O. A. Usage of microemulsion for the extraction of o-phthalic acid ether from the soil, followed by decomposition of microemulsions with simultaneous concentration and gas chromatographic determination of target components / Vestnik Moskovskogo Universiteta. Ser. 2. Khimiya. 2017. Vol. 58. N 2. P. 83 - 88 [in Russian]. 